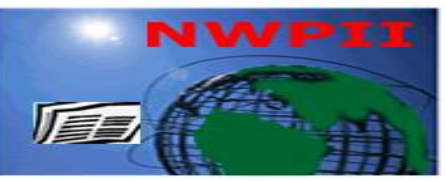

American Journal of Biomedical Sciences

ISSN: 1937-9080

nwpii.com/ajbms

\title{
Anti-oxidant, Anti-inflammatory and Anti-apoptotic Effect of Adiponectin on Cerebral Ischemia Reperfusion Injury in Rats
}

\author{
Mona A. Said and Hend A. Abdallah
}

Physiology department, Faculty of Medicine, Benha University, Egypt.

"Corresponding Author

Mona A. Said

Physiology department, Benha Faculty of Medicine

Benha, Qalubia

Egypt

Email: dr.monaabdelazim@gmail.com - Mona.said@fmed.bu.edu.eg

Mobile: 00201117060320

Received:10 January 2019; | Revised:30 January 2019; | Accepted: 10 June 2019

\begin{abstract}
Background: Ischemic stroke is a major cause of death and disability worldwide. Despite decades of intense research, the beneficial treatment of stroke remains limited. Adiponectin, a circulating adiposederived hormone, has beneficial actions on cardio- and cerebrovascular disorders. A low level of plasma adiponectin is associated with ischemic cerebrovascular disease. In the present study, the role of adiponectin in the pathogenesis of acute cerebral injury was investigated. Rats were divided into three groups: (i) Sham operated group; (ii) Ischemia/reperfusion (I/R) group, rats were subjected to one hour middle cerebral artery occlusion followed by 23 hours of reperfusion (I/R); (iii) Adiponectin-treated group, adiponectin $(0.5 \mathrm{mg} / \mathrm{kg})$ was injected through jugular vein 10 minutes after the onset of reperfusion. Adiponectin supplementation improved neurological function and resulted in reduction in infarction size, and brain edema, brain contents of malondialdehyde (MDA), brain levels of nitric oxide (NO) levels, tumor necrosis factor-alpha (TNF- a ) and caspase-3. Moreover it enhanced SOD (superoxide dismutase). Results of the present study demonstrate that adiponectin exerts a potent cerebroprotective effect against I/R injury through its anti-inflammatory and anti-oxidant action and anti-apoptotic mechanisms. It might be a potential target for ischemic stroke therapy.
\end{abstract}

Keywords: Ischemic stroke, Adiponectin, Cerebroprotective

\section{List of abbreviations}

BBB; Blood brain barrier; CNS, Central nervous system; ELISA, Enzyme linked immunoassay; eNOS, Endothelial nitric oxide synthase; iNOS, Inducible niric oxide synthase, I/R, Ishemia/Reperfusion; MCA, Middle cerebral artery;
MDA, Malondialdehyde; nNOS, Neuronal nitric oxide synthase; NO, Nitric oxide; SOD, Superoxide dismutase; TNF- a, Tumor necrosis factor alpha; tPA, tissue plasminogen activator; ROS, Reactive oxygen species. 


\section{Introduction}

Cerebral ischemic injury is a major cause of death and disability all over the world ${ }^{[1]}$. It is the third leading cause of death, after cardiovascular diseases and cancer ${ }^{[2]}$. Ischaemia-reperfusion injury $(\mathrm{I} / \mathrm{R})$ of the central nervous system (CNS) is a complex interplay between biochemical, vascular and cellular factors ${ }^{[3]}$ that may occur after cerebral ischemia, traumatic head injury, carotid endarterectomy or aneurysm repair ${ }^{[4]}$.

Cerebral ischemia is a major type of stroke, accounting for about $80 \%$ of stroke cases ${ }^{[1]}$. Ischemic stroke results from a temporary or permanent reduction of cerebral blood flow that leads to structural and functional damage in different brain regions during ischemia ${ }^{[5]}$ and reperfusion ${ }^{[6]}$. Restoration of blood supply, referred to as reperfusion is a desired goal for acute stroke treatment. Reperfusion can be achieved either by using thrombolytic reagents such as tissue plasminogen activator (tPA), or through mechanical removal of thrombi. Spontaneous reperfusion also occurs after ischemic stroke. However, despite the beneficial effect of restoring oxygen supply by reperfusion, it also causes deleterious effect compared with permanent ischemia. The main mechanisms of reperfusion injury include oxidative stress, mitochondrial mechanisms, leukocyte infiltration, platelet activation and aggregation, inflammation, complement activation, apoptosis and blood-brain-barrier (BBB) disruption, which ultimately lead to brain edema or hemorrhagic transformation and eventually causing significant neuron death and neurological dysfunctions ${ }^{[7,8]}$.

Despite decades of intensive research, the beneficial treatment of stroke remains limited ${ }^{[9]}$. In light of this, the search for effective means ameliorating cerebral ischemia-reperfusion injury is one of the major problems of experimental medicine and biology ${ }^{[10]}$. Emerging evidence suggests that adiponectin may be one such potential therapy $[11,12]$

Adiponectin is one of adipose cell-derived protein hormones secreted by the adipose tissue, abundant in human plasma, and can be expressed in the bone marrow, cardiomyocytes, osteoblasts, and CNS ${ }^{[13]}$. It has anti-inflammatory, anti-oxidant, anti-atherogenic and antidiabetic effects, thus exhibiting protective effects on cells, tissues and organs. It exerts its physiological functions by activating two membrane receptors, adiponectin receptor 1 and 2 that are prominently expressed in skeletal muscle, adipose tissue, liver, and brain ${ }^{[14}$ 15].

Recently, a cross-sectional study showed that plasma adiponectin levels are decreased in patients with ischemic cerebrovascular disease [16]. Furthermore, a clinical study has suggested an association between hypoadiponectinemia and increased mortality after ischemic stroke and a negative correlation between adiponectin levels and initial infarct volume. However, the involvement of adiponectin in cerebrovascular disease and its potential mechanisms have not been completely elucidated $^{[17]}$.

So we aimed in this study to investigate the neuroprotective role of adiponectin against the development of ischemic stroke in the rat model of focal cerebral $\mathrm{I} / \mathrm{R}$ injury and its potential underlying mechanisms focusing on its possible anti-oxidative, anti-inflammatory and anti-apoptotic effects.

\section{Materials and Methods}

\subsection{Animals}

Thirty adult male albino Wistar rats weighing 230 - $250 \mathrm{~g}$ were housed in plastic cages at a controlled temperature $\left(25 \pm 3^{\circ} \mathrm{C}\right),(50 \pm 10 \%)$ humidity, with alternating $12 \mathrm{~h}$ light and dark cycles. They were allowed to standard chow pellets and drinking water ad libitum. The animals were left to accommodate for one week before the experiment. Experiments were performed between 8 and 10 a.m. This work was carried out according to the international guidelines for care and use of laboratory animals, and the experimental protocol was ethically approved by the Animal Care Committee, Faculty of Medicine, Benha University.

\subsection{Experimental design}

Thirty Rats were randomly divided into three groups ( $\mathrm{n}=10$ per group):

(i)Sham operation group, rats were subjected to the surgical procedures without ischemia repefusion (I/R). 
(ii)Ischemia/reperfusion (I/R) group, rats were subjected to $1 \mathrm{~h}$ middle cerebral artery occlusion followed by $23 \mathrm{~h}$ reperfusion (I/R).

(iii) Adiponectin-treated group (I/R + Adiponectin), adiponectin $(0.5 \mathrm{mg} / \mathrm{kg})$ was administered through jugular vein 10 minutes after the onset of reperfusion. Adiponectin was provided by Sigma Aldrich, (St. Louis, MO, USA).

\subsection{Induction of middle cerebral artery occlusion}

The rat model of left cerebral ischemiareperfusion was established according to a previously published method of Longa et al. (1989). Briefly, overnight-fasted rats were anesthetized with $10 \%$ chloral hydrate $(3.5 \mathrm{ml} / 100 \mathrm{~g}$, i.p. injection; Tianjin Kemiou Chemical Reagent Co., Ltd., Tianjin, China). After the skin was exposed through a midline neck incision, the left common carotid artery, external carotid artery, and internal carotid artery were exposed and isolated through a ventral midline incision. After electrocauterization of the occipital artery, the external carotid artery, distal to the heart, was ligated with two surgical sutures. The common carotid artery and internal carotid artery were clamped. The silk sutures around the external carotid artery were lifted toward the common carotid artery ensuring that the external carotid artery and common carotid artery were placed at the same plane. A gap was then made at the bifurcation of the external carotid artery adjacent to the common carotid artery, and a monofilament suture (Beijing Sunbio Biotech Co., Ltd., Beijing, China) was slowly inserted from the incision close to the internal carotid artery. The suture was then withdrawn from the internal carotid artery until resistance was felt at the bifurcation of the external carotid artery. Furthermore, the suture tip almost reached the left middle cerebral artery, thereby occluding blood flow it. The suture was fixed and the wounds were then sutured. The animals were subsequently returned to their cages (at $26^{\circ} \mathrm{C}$ ). After one hour of ischemia, rats were reanesthetized via ether inhalation. The suture was then lifted slightly until the resistance was felt indicating that the suture tip had reached the external carotid artery. Blood flow in the left middle cerebral artery resumed as a result. Reperfusion was allowed for 23 hours. Rectal temperature was maintained between $36.5^{\circ} \mathrm{C}$ and $37.2^{\circ} \mathrm{C}$ with a homeothermic blanket to avoid cerebral hypothermia. Successful establishment of the model was confirmed by the right forelimb flexion or right side circling after the animals recovered from the anesthesia. The same protocol was applied for sham-operated rats, but only the arteries were isolated ${ }^{[18]}$.

\subsection{Mortality score and neurological deficit score}

The mortality of rats in each group was calculated according to the formula: Percentage mortality $=$ number of deaths in the group/total number of rats in the group $\times 100 \%$. After onehour ischemia and 23-hour reperfusion, neurological deficits of rats were evaluated according to a previously described 5-grade scale ${ }^{[18]}$. The scale was graded as follows: 0 point: rats have no neurological symptoms, 1 point: minor defects (rats cannot fully extend the contralateral forepaw), 2 points: moderate defects (rats circle toward the contralateral side), 3 points: severe defects (rats fall toward the contralateral side), 4 points: rats cannot walk spontaneously or depressed level of consciousness.

\subsection{Measurement of brain water content}

Cerebral edema was determined by measuring the brain water content according to the wet - dry method ${ }^{[19]}$. After $23 \mathrm{~h}$ of reperfusion, animals were anesthetized with $10 \%$ chloral hydrate $(3.5 \mathrm{ml} / \mathrm{kg})$ and decapitated. The brains were rinsed with saline and separated into ischemic and non-ischemic hemispheres, then immediately weighed to gain the wet weight (WW). The brains were placed in an oven at $100^{\circ} \mathrm{C}$ for $24 \mathrm{~h}$ and weighed to obtain the dry weight (DW). The brain water content (\%) was measured using the following formula: (WW - DW) / WW x $100 \%$.

\subsection{Measurement of the infarction size}

The brains were carefully dissected out on ice. Coronal brain sections ( $2 \mathrm{~mm}$ thickness) were made from the forebrain region and immersed with $2 \% 2$, 3, 5 triphenyltetrazolium chloride solution at $37^{\circ}$

$\mathrm{C}$ for $30 \mathrm{~min}$. Infarct size was calculated according to the following formula:

Percentage infarct size $=$ the volume of the cerebral hemisphere on the normal side - The non- 
infarct area on the ischemic side/the volume of the cerebral hemisphere on the normal side $\times 100 \%$. [20].

\subsection{Tissue collection}

Brain samples were washed with isotonic saline and homogenized in either, ice-cold saline solution for malondialdehyde (MDA) and nitric oxide (NO) determination, or phosphate buffered saline for other parameters. Supernatant was obtained by centrifuging the homogenate at $12000 \mathrm{rpm}$ for $20 \mathrm{~min}^{[21]}$.

\subsection{Assessment of brain lipid peroxides content measured as malondialdehyde (MDA)}

As a major indicator of oxidative stress, lipid peroxides were measured as MDA level in the brain homogenates. The principle of the assay depends on the reaction of MDA with thiobarbituric acid in acidic medium when incubated for $45 \mathrm{~min}$ at $95^{\circ}$ C. The resultant pink color was extracted by nbutanol and the absorbance was measured at 535 $\mathrm{nm}$ by a spectrophotometer (UV-1601; Shimadzu, Kyoto, Japan) ${ }^{[22]}$.

\subsection{Assessment of brain nitric oxide (NO) content measured as total nitrates/nitrites}

This assay determines total nitric oxide based on the chemical reduction of nitrate to nitrite by vanadium trichloride, followed by the colorimetric detection of nitrite as an azo dye product of Griess reaction at $540 \mathrm{~nm}^{[23]}$.

\subsection{Determination of brain superoxide dismutase (SOD) activity}

SOD activity was determined by commercial kit (R\&D Systems, Inc., USA), according to the method of Beauchamp and Fridovich (1971). The assay is based on the conversion of nitro blue tetrazolium (NBT) to NBT-diformazan by superoxide ions generated from the reaction of xanthine and oxygen catalyzed by xanthine oxidase. SOD reduces superoxide ion concentration, and hinders the appearance of NBT-diformazan. The absorbance was measured at $550 \mathrm{~nm}$. SOD activity in samples was determined from a standard curve [24].

\subsection{Assessment of brain tumor necrosis factor} alpha (TNF- $\alpha$ ) content

TNF- $a$, content were determined in brain homogenates by rat specific RayBio TNF-alpha ELISA kits (RayBiotech, Inc., USA). The assay procedure was followed as mentioned in the manuals and the absorbance of the yellow color was measured at $450 \mathrm{~nm}^{[25]}$.

\subsection{Assessment of brain caspase-3 level}

The level of brain caspase-3 was measured by a USCN ELISA kit (Life Science Inc., PRC). The finally developed yellow color was measured at 450 $\mathrm{nm}$ using a microplate reader ${ }^{[20,21]}$.

\subsection{Statistical analysis}

All analyses were performed using the program Statistical Package for Social Sciences version 19 (SPSS Inc, Chicago, IL, USA). The data are presented as the mean \pm standard deviation (SD). Comparisons between groups were analyzed by using one-way Analysis of Variance (ANOVA) followed by post-hoc LSD test. Probability of chance $(\mathrm{P}$ value $)<0.05$ was considered statistically significant.

\section{Results}

\subsection{Effect of adiponectin on the mortality rate} and neurological function in rats exposed to cerebral $\mathbf{I} / \mathbf{R}$ injury

The mortality percentage was increased from 0 in sham operated group to $30 \%$ in I/R group and it decreased by adipnectin administration to be $10 \%$. As shown in table 1, the neurological deficit scores were significantly increased from 0 in sham operated group to $2.83 \pm 0.18$ in $\mathrm{I} / \mathrm{R}$ group $(\mathrm{P}<$ 0.05). Adiponectin administration significantly decreased the neurological deficit to $1.15 \pm 0.06(\mathrm{P}$ $<0.05$ ) as compared with I/R group.

\subsection{Effect of adiponectin on brain water content in rats exposed to cerebral $I / R$ injury \\ As shown in table 1 and fig 1 , the brain water content in the ischemic area of $\mathrm{I} / \mathrm{R}$ group were significantly increased from $54.50 \pm 4.32$ in sham operated group to $85.12 \pm 6.96$ in $\mathrm{I} / \mathrm{R}$ group $(\mathrm{P}<$ 0.05). Treatment with adiponectin significantly}


decreased the brain water content to $60.85 \pm 5.13$ $(\mathrm{P}<0.05)$ when compared with $\mathrm{I} / \mathrm{R}$ group.

\subsection{Effect of adiponectin on cerebral infarction} size in rats exposed to cerebral $I / R$ injury

As shown in table 1 and fig. $1 \& 2$, cerebral $\mathrm{I} / \mathrm{R}$ induced a significant increase in cerebral infarction size from 0 in the sham operated group to $70.01 \pm 1.67 \mathrm{in} \mathrm{I} / \mathrm{R}$ group. Administration of adiponectin induced a significant decrease in cerebral infarction size to $32.33 \pm 0.64$ compared to $\mathrm{I} / \mathrm{R}$ group $(\mathrm{P}<0.05)$.

\subsection{Effect of adiponectin on total lipid peroxides measured as malondialdehyde (MDA) in rats exposed to cerebral $\mathbf{I} / \mathbf{R}$ injury}

As shown in table 2 and Fig. 3, cerebral I/R resulted in a significant increase in brain MDA content from $2.68 \pm 0.22$ in the sham operated group to $6.75 \pm 0.55(\mathrm{P}<0.05)$. Adiponectin induced a significant decrease in brain MDA contents to $3.01 \pm 0.32$ as compared to $\mathrm{I} / \mathrm{R}$ group $(\mathrm{P}<0.05)$.

3.5 Effect of adiponectin on brain nitric oxide (NO) content measured as total nitrate/nitrites in rats exposed to $I / R$ injury

Table 2 and fig. 3 showed that brain NO content was significantly elevated following cerebral I/R from $9.62 \pm 0.94$ in sham operated group to $19.88 \pm 1.23(\mathrm{P}<0.05)$ and that administration of adiponectin caused a significant reduction in brain NO content to $11.45 \pm 1.36$ as compared to I/R group $(\mathrm{P}<0.05)$.

Table 1 :Neurological function, infarction size, brain water content in all experimental groups

\begin{tabular}{|c|c|c|c|}
\hline Groups & $\begin{array}{c}\text { Group I (Sham } \\
\text { operated) }\end{array}$ & $\begin{array}{c}\text { Group II } \\
\text { (I/R) }\end{array}$ & $\begin{array}{c}\text { Group III } \\
\text { (I/R + Adiponectin) }\end{array}$ \\
\hline Parameter & 0 & $2.83 \pm 0.18^{*}$ & $1.15 \pm 0.06^{\#}$ \\
\hline Infarction size (\%) & 0 & $70.01 \pm 1.67^{*}$ & $32.33 \pm 0.64^{\#}$ \\
\hline Brain water content (\%) & $54.50 \pm 4.32$ & $85.12 \pm 6.96^{*}$ & $60.85 \pm 5.13^{\#}$ \\
\hline
\end{tabular}

Data is expressed as mean \pm standard deviation, $P$. value $=$ probability of chance, $P<0.05$ is significant tested by using One-way analysis of variance (ANOVA) test and Post Hoc multiple comparisons (LSD test).

"Significant difference $v s$ sham operated group

\# Significant difference $v s \mathrm{I} / \mathrm{R}$ group. 
Table 2 :Brain content of MDA, NO and SOD in all experimental groups

\begin{tabular}{|c|c|c|c|}
\hline Groups & \multirow{2}{*}{$\begin{array}{c}\text { Group I } \\
\text { (Sham operated) }\end{array}$} & $\begin{array}{c}\text { Group II } \\
(\mathrm{I} / \mathrm{R})\end{array}$ & $\begin{array}{c}\text { Group III } \\
\text { (I/R + Adiponectin) }\end{array}$ \\
\hline MDA (mM/100 mg tissue) & $2.68 \pm 0.22$ & $6.75 \pm 0.55^{*}$ & $3.01 \pm 0.32^{\#}$ \\
\hline NO (mM/100 mg tissue) & $9.62 \pm 0.94$ & $19.88 \pm 1.23^{*}$ & $11.45 \pm 1.36^{\#}$ \\
\hline SOD (U/100 mg tissue) & $2.45 \pm 0.14$ & $0.99 \pm 0.05^{*}$ & $1.96 \pm 0.03^{\#}$ \\
\hline
\end{tabular}

Data is expressed as mean \pm standard deviation, $P$. value $=$ probability of chance, $P<0.05$ is significant tested by using One-way analysis of variance (ANOVA) test and Post Hoc multiple comparisons (LSD test).

"Significant difference $v s$ sham operated group

\# Significant difference $v s \mathrm{I} / \mathrm{R}$ group.

Table 3 :Brain levels of TNF-a and caspase 3 in all experimental groups

\begin{tabular}{|c|c|c|c|}
\hline Groups & \multirow{2}{*}{$\begin{array}{c}\text { Group I } \\
\text { (Sham operated) }\end{array}$} & $\begin{array}{c}\text { Group II } \\
\text { (I/R) }\end{array}$ & $\begin{array}{c}\text { Group III } \\
\text { (I/R + Adiponectin) }\end{array}$ \\
\cline { 1 - 4 } Parameter & $49.76 \pm 2.58$ & $135.36 \pm 3.87^{*}$ & $63.34 \pm 2.64^{\#}$ \\
\hline Caspase-3 (Pg/100 mg tissue) & $10.18 \pm 0.77$ & $28.22 \pm 0.46^{*}$ & $12.06 \pm 0.38^{\#}$ \\
\hline
\end{tabular}

Data is expressed as mean \pm standard deviation, $P$. value $=$ probability of chance, $P<0.05$ is significant tested by using One-way analysis of variance (ANOVA) test and Post Hoc multiple comparisons (LSD test).

*Significant difference $v s$ sham operated group

\# Significant difference $v s \mathrm{I} / \mathrm{R}$ group.

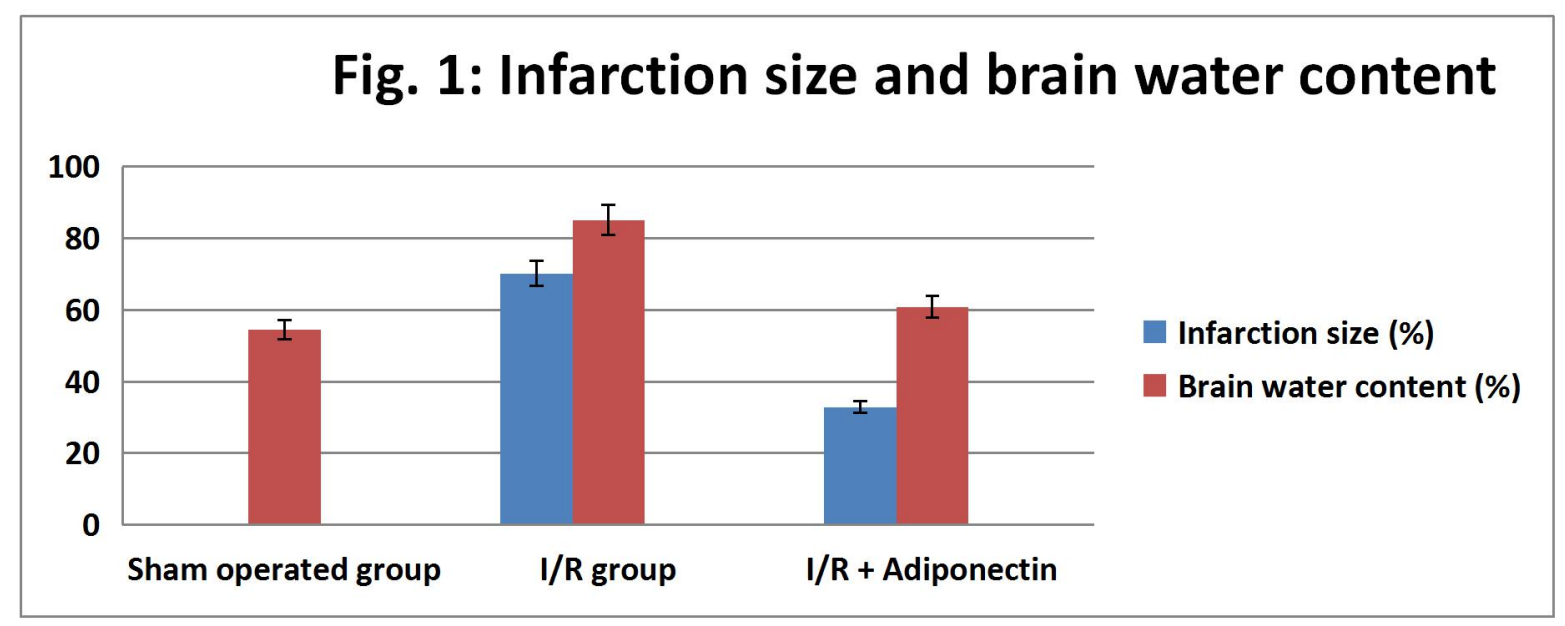

Figure 1 : Infarction size and brain water content

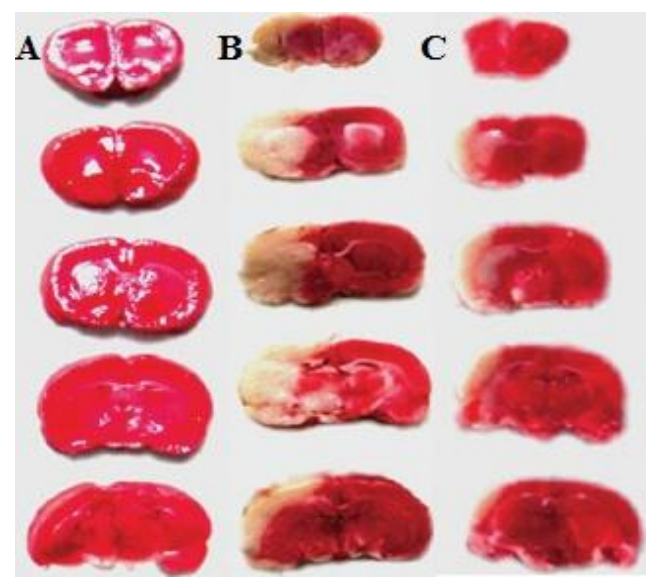

Figure 2 : Infarction size in all experimental groups (A) Sham operated group, (B): I/R group and (C): I/R + Adiponectin 


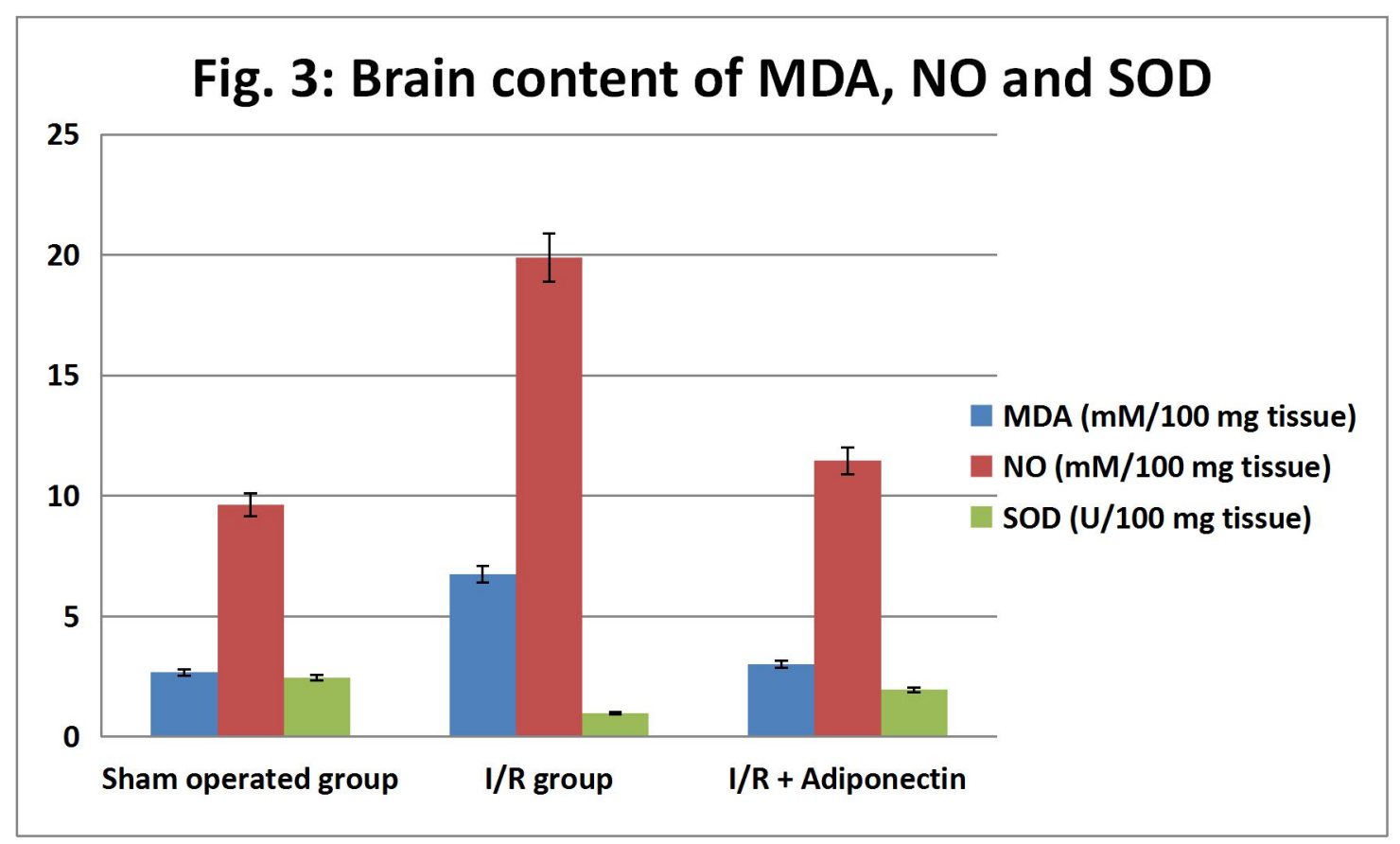

Figure 3 : Brain content of MDA, NO and SOD

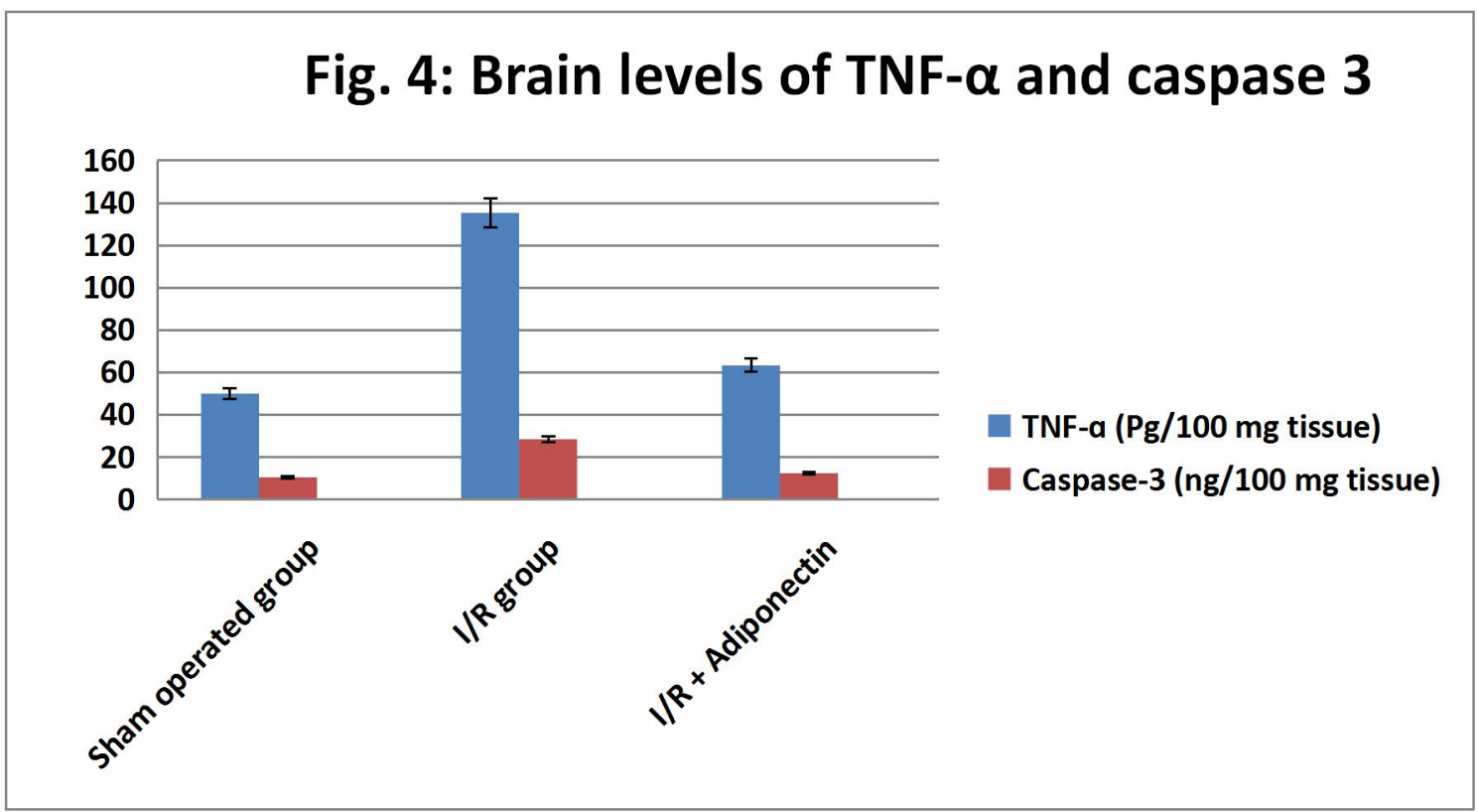

Figure 4 : Brain levels of TNF- $\alpha$ and caspase 3

\section{Discussion}

Cerebral ischemic injury is the most common cerebrovascular disorder. The association between adiponectin and cerebral ischemia remains unclear. Epidemiological studies have shown that hypoadiponectinemia could be a useful biomarker for the presence of ischemic stroke and increased mortality after ischemic stroke [16, 17]. Plasma adiponectin values may help predict neurological severity and functional outcome in ischemic stroke patients ${ }^{[26]}$.

Thus in the present study, we demonstrate that an adipose-derived hormone, adiponectin, protects the brain from acute ischemic injury in a rat model of focal cerebral I/R done through MCA occlusion.

The current study showed a significant decrease of neurological function, induction of cerebral infarction and brain edema after one hour of ischemia and 23 hours of reperfusion. These 
findings are consistent with those of Melani et al. (2006) ${ }^{[27]}$. In this research, we demonstrated that treatment with adiponectin could reduce brain infarct size and brain edema while improving neurological function after focal cerebral I/R injury. These finding were in agreement to the previous studies $[11,12,28]$.

Oxidative stress, stemming from distortion of the equilibrium between production and scavenging of free radicals, is one of the most important pathological mechanisms underlying $\mathrm{I} / \mathrm{R}$ injury. Cerebral $I / R$ injury is characterized by overproduction of reactive oxygen species and exhaustion of brain natural defense systems with consequent neuronal deterioration and delayed neuronal death ${ }^{21,29]}$. Sudden bursts of free radicals and reactive oxygen species (ROS) observed during I/R injury accumulate and attack proteins, lipids and nucleic acids leading to lipid peroxidation, cellular membrane damage, impairment of cellular functions and DNA fragmentation ${ }^{[30,31]}$. MDA is considered as the most sensitive marker of lipid peroxidation. The high brain lipid peroxides content and low concentration of endogenous antioxidants renders it highly susceptible to oxidative damage ${ }^{[32]}$. Beside oxidative stress, nitrosative stress is another pathological mechanism significantly contributing to neuronal death induced by excessive nitric oxide (NO) production through nitric oxide synthases (NOSs) ${ }^{[33]}$. The role of $\mathrm{NO}$ in pathogenesis of ischemic brain damage is controversial. Nitric oxide is considered as a double-edged sword. Some evidence has been accumulated that NO plays either neurotoxic or neuroproective roles during the process of cerebral ischemia and reperfusion. The amount and the source of NO are crucial factors determining its effects in cerebral ischemia. Nitric oxide produced by endothelial nitric oxide synthase (eNOS) has been suggested to exert beneficial effects during cerebral ischemia-reperfusion [34]. Neuronal NOS (nNOS) and especially inducible NOS (iNOS) activities have been proposed to be damaging to the ischemic brain ${ }^{[35]}$. Cerebral ischemia up regulates inducible nitric oxide synthase (iNOS), producing excessive nitric oxide which reacts with superoxide to form peroxynitrite resulting in cellular machinery dysfunction and neuronal death ${ }^{[30,36,37]}$. The current study revealed a significant increase in MDA and NO and a significant decrease in brain SOD level indicating the involvement of oxidative stress in MCA occlusion induced cerebral $\mathrm{I} / \mathrm{R}$ injury. The antioxidant effect of adiponectin against I/R-induced brain damage can be attributed to its ability to reduce the elevated brain levels of MDA and NO together with enhancement of SOD in rats exposed to cerebral $I / R$. The finding of this study was in agreement to Nishimura et al. (2008) who provided a causal evidence that adiponectin exerts its cerebroprotective effect via an eNOS-dependent mechanism ${ }^{[12]}$. Song et al. (2013) demonstrated that the neuroprotective action of adiponectin may result from the promotion of antioxidant capacity by inhibiting the NADPH oxidase 2 signaling system [28]

Similarly, expression of inflammatory cytokines in brain tissues was detected after brain I/R injury [21, 38]. Oxidative stress activates the expression of pro-inflammatory cytokines ${ }^{[39]}$. One of the most important cytokines released during ischemia/reperfusion is TNF- $\alpha$. This proinflammatory cytokine can contribute to the pathogenesis of $\mathrm{I} / \mathrm{R}$ injury by induction of cell adhesion molecules thereby enhancing reactive oxygen species production, facilitating leukocyte infiltration, and exaggerating the inflammatory response with subsequent cerebral damage [40]. Blockade of TNF- $\alpha$ receptors could reduce brain infarct volume after transient focal ischemia in rats ${ }^{[41]}$. The current study also revealed a significant increase in brain TNF-a levels in MCA occlusion induced I/R injury. Adiponectin administration caused a significant reduction in the brain levels of TNF- $\alpha$ in rats exposed to cerebral I/R. Chen et al. (2009) demonstrated that adiponectin displays a potent cerebroprotective activity via an antiinflammatory effect and that nuclear factor kappaB $(\mathrm{NF}-\mathrm{kB})$ is a key component in this process ${ }^{[11]}$. Adiponectin suppresses systemic inflammation through upregulation of anti-inflammatory cytokines (e.g., interleukin (IL)-10 and IL-1 receptor antagonist) and suppression of proinflammatory cytokines (e.g. TNF-a and interferon-g) ${ }^{[42]}$. Adiponectin also inhibits the interaction between the endothelium and leukocytes in cerebral I/R. Therefore adiponectin might prevent the secondary insult caused by the inflammatory reaction ${ }^{[43]}$. 
Activation of apoptotic mechanisms and controlled neuronal death were observed following cerebral $\mathrm{I} / \mathrm{R}^{[44]}$. Apoptosis is achieved by a cascade of intracellular cysteine aspartase specific proteases ,named caspases, that mediate cell death and inflammation. There are two types of caspases: initiator caspases (caspases 8, 10, 9, and 2) and effector caspases (caspases 3, 7 and 6). The effector caspases are activated by initiator ones ${ }^{[45]}$. Among all members of the caspase family, caspase- 3 is most abundant in the brain [46]. Activation of caspase-3 is considerably implicated in ischemic cell death ${ }^{[47]}$. Caspase- 3 has been found to increase soon after forebrain ischemia with a persistent increase after reperfusion ${ }^{[48]}$. Activation of caspase3 results in cleavage of actin and proteins that are vital for DNA repair and cell stability, causing cell death primarily by apoptosis ${ }^{[49]}$. ROS binding of TNF- $\alpha$ take part in the induction of apoptosis and promotion of caspases activation leading to nuclear damage $[50,51]$. In this study, MCA occlusion induced $\mathrm{I} / \mathrm{R}$ injury caused a significant increase in caspase 3 level. Treatment of rats exposed to cerebral I/R with adiponectin led to a significant decrease in the brain levels of caspase- 3 and this is congruent with the previous studies which found the role of adiponectin in attenuating endothelial and neuronal apoptosis ${ }^{[17,36]}$.

\section{Conclusion}

The present observations indicate that adiponectin acts as an endogenous modulator of cerebral $\mathrm{I} / \mathrm{R}$ injury and this may be attributed to lower the levels of lipid peroxidation, antiinflammatory cytokines and pro-apoptotic caspase-3 and enhancement of antioxidant enzymes. Thus, adiponectin could represent a potential therapeutic target for the prevention and treatment of ischemic stroke.

\section{Conflict of interest}

The authors declare that there is no conflict of interest.

\section{References}

1 Della-Morte D, Guadagni F, Palmirotta R, Testa G, Caso V, Paciaroni M, Abete P, Rengo F, Ferroni P, Sacco RL, Rundek T. Genetics of ischemic stroke, stroke-related risk factors, stroke precursors and treatments. Pharmacogenomics 2012; 13(5): 595-613 DOI: $10.2217 /$ pgs.12.14

2 Stapf C, Mohr JP. Ischemic stroke therapy. Annu Rev Med 2002; 53: 453-475 DOI: 10.1146/annurev.med.53.082901.104106

3 Abela CB, Homer-Vanniasinkham S. Clinical implications of ischaemia-reperfusion injury. Pathophysiology 2003; 9(4): 229-240 [PMID: 14567926]

4 Winquist, R.J.; Kerr, S. Cerebral ischemiareperfusion injury and adhesion. Neurology, 1997, 49(5), S23 - 6. doi: http://dx.doi.org/ 10.1212/WNL.49.5 Suppl 4.S23.

5 Lo EH, Dalkara T, Moskowitz MA. Mechanisms, challenges and opportunities in stroke. Nat Rev Neurosci 2003; 4(5): 399-415 DOI: 10.1038/nrn1106

6 Yanpallewar SU, Hota D, Rai S, Kumar M, Acharya SB. Nimodipine attenuates biochemical, behavioral and histopathological alterations induced by acute transient and longterm bilateral common carotid occlusion in rats. Pharmacol Res 2004; 49(2): 143-150 [PMID: 14643694]

$7 \quad \mathrm{~L} \mathrm{~L}, \mathrm{X} \mathrm{W}, \mathrm{Z}$ Y. Ischemia-reperfusion Injury in the Brain: Mechanisms and Potential Therapeutic Strategies. Biochem Pharmacol (Los Angel) 2016; 5(4)DOI: 10.4172/2167$\underline{0501.1000213}$

8 Sahota P, Savitz SI. Investigational therapies for ischemic stroke: neuroprotection and neurorecovery. Neurotherapeutics 2011; 8(3): 434-451 DOI: $10.1007 / \mathrm{s} 13311-011-0040-6$

9 Ozen OA, Cosar M, Sahin O, Fidan H, Eser O, Mollaoglu H, Alkoc O, Yaman M, Songur A. The protective effect of fish n-3 fatty acids on cerebral ischemia in rat prefrontal cortex. Neurol Sci 2008; 29(3): 147-152 DOI: 10.1007/s10072-008-0926-1

10 Shcherbak NS, Galagudza MM, Kuzmenkov AN, Ovchinnikov DA, Mitrofanova LB, Barantsevich ER, Shlyakhto EV. A new rat 
model of reversible global cerebral ischemia. Bull Exp Biol Med 2012; 152(5): 656-658 [PMID: 22803158]

11 Chen B, Liao WQ, Xu N, Xu H, Wen JY, Yu CA, Liu XY, Li CL, Zhao SM, Campbell W. Adiponectin protects against cerebral ischemia-reperfusion injury through antiinflammatory action. Brain Res 2009; 1273: 129-137 DOI: 10.1016/j.brainres.2009.04.002

12 Nishimura M, Izumiya Y, Higuchi A, Shibata R, Qiu J, Kudo C, Shin HK, Moskowitz MA, Ouchi N. Adiponectin prevents cerebral ischemic injury through endothelial nitric oxide synthase dependent mechanisms. Circulation 2008; 117(2): 216-223 DOI: 10.1161/CIRCULATIONAHA.107.725044

13 Psilopanagioti A, Papadaki H, Kranioti EF, Alexandrides TK, Varakis JN. Expression of adiponectin and adiponectin receptors in human pituitary gland and brain. Neuroendocrinology 2009; 89(1): 38-47 DOI: $\underline{10.1159 / 000151396}$

14 Xie, H.; Zhang, L.; Li, Z.; Du, W. Roles of adiponectin in alleviating myocardial ischemia-reperfusion injury in rats with remote ischemic postconditioning. Biomed. Res., 2017, 28(12),5252-5256.

http://www.alliedacademies.org/articles/rolesof-adiponectin-in-alleviating-myocardialischemiareperfusion-injury-in-rats-withremote-ischemic-postconditioning.html

15 Yang Y, Hu W, Jiang S, Wang B, Li Y, Fan C, Di S, Ma Z, Lau WB, Qu Y. The emerging role of adiponectin in cerebrovascular and neurodegenerative diseases. Biochim Biophys Acta 2015; 1852(9): 1887-1894 DOI: 10.1016/j.bbadis.2015.06.019

16 Chen MP, Tsai JC, Chung FM, Yang SS, Hsing LL, Shin SJ, Lee YJ. Hypoadiponectinemia is associated with ischemic cerebrovascular disease. Arterioscler Thromb Vasc Biol 2005; 25(4): 821-826 DOI: 10.1161/01.ATV.0000157784.25920.a7

17 Efstathiou SP, Tsioulos DI, Tsiakou AG, Gratsias YE, Pefanis AV, Mountokalakis TD. Plasma adiponectin levels and five-year survival after first-ever ischemic stroke. Stroke 2005; 36(9): 1915-1919 DOI: 10.1161/01.STR.0000177874.29849.f0
18 Longa EZ, Weinstein PR, Carlson S, Cummins R. Reversible middle cerebral artery occlusion without craniectomy in rats. Stroke 1989; 20(1): 84-91 [PMID: 2643202]

19 Hatashita S, Hoff JT, Salamat SM. Ischemic brain edema and the osmotic gradient between blood and brain. J Cereb Blood Flow Metab 1988; 8(4): 552-559 DOI: $\underline{10.1038 / \mathrm{jcbfm} .1988 .96}$

20 Pithadia, A.B.; Panchal, S.S.; Patel, D.J. Neuroprotective effects of potassium channel openers on cerebral ischemia - reperfusion injury in diabetic rats. Bulletin of Faculty of Pharmacy, Cairo University, 2017, 55(1), 95 100.https://doi.org/10.1016/j.bfopcu.2016.09.0 $\underline{02 .}$

21 Ahmed MA, El Morsy EM, Ahmed AA. Pomegranate extract protects against cerebral ischemia/reperfusion injury and preserves brain DNA integrity in rats. Life Sci 2014; 110(2): 61-69 DOI: 10.1016/j.1fs.2014.06.023

22 Mihara, M.; Uchiyama, M. Determination of malonaldehyde precursor in tissues by thiobarbituric acid test. Anal. Biochem, 1978, 86(1),271-8.

https://www.sciencedirect.com/science/article/ pii/0003269778903421

23 Miranda KM, Espey MG, Wink DA. A rapid, simple spectrophotometric method for simultaneous detection of nitrate and nitrite. Nitric Oxide 2001; 5(1): 62-71 DOI: 10.1006/niox.2000.0319

24 Beauchamp, C.; Fridovich, I. Superoxide dismutase: improved assays and an assay applicable to acrylamide gels. Anal Biochem., 1971,44,276-87.https://doi.org/10.1016/00032697(71)90370-8.

25 Bonavida B. Immunomodulatory effect of tumor necrosis factor. Biotherapy 1991; 3(2): 127-133 [PMID: 2054253]

26 Kuwashiro T, Ago T, Kamouchi M, Matsuo R, Hata J, Kuroda J, Fukuda K, Sugimori H, Fukuhara M, Awano H, Isomura T, Suzuki K, Yasaka M, Okada Y, Kiyohara Y, Kitazono T. Significance of plasma adiponectin for diagnosis, neurological severity and functional outcome in ischemic stroke - Research for Biomarkers in Ischemic Stroke (REBIOS). 
Metabolism 2014; 63(9): 1093-1103 DOI: 10.1016/j.metabol.2014.04.012

27 Melani A, Amadio S, Gianfriddo M, Vannucchi MG, Volonte C, Bernardi G, Pedata F, Sancesario G. P2X7 receptor modulation on microglial cells and reduction of brain infarct caused by middle cerebral artery occlusion in rat. J Cereb Blood Flow Metab 2006; 26(7): 974-982 DOI: $10.1038 / \mathrm{sj} . j \mathrm{cbfm} .9600250$

28 Song W, Huo T, Guo F, Wang H, Wei H, Yang Q, Dong H, Wang Q, Xiong L. Globular adiponectin elicits neuroprotection by inhibiting NADPH oxidase-mediated oxidative damage in ischemic stroke. Neuroscience 2013; 248: 136-144 DOI: 10.1016/j.neuroscience.2013.05.063

29 Tian J, Li G, Liu Z, Zhang S, Qu G, Jiang W, Fu F. ND-309, a novel compound, ameliorates cerebral infarction in rats by antioxidant action. Neurosci Lett 2008; 442(3): 279-283 DOI: 10.1016/j.neulet.2008.07.033

30 Schmidley, J . W . Free radicals in central nervous system ischemia. Stroke, 1990, 21(7), 1086-90.

https://www.ahajournals.org/doi/10.1161/01.S

TR.21.7.1086.

31 Thiyagarajan M, Sharma SS. Neuroprotective effect of curcumin in middle cerebral artery occlusion induced focal cerebral ischemia in rats. Life Sci 2004; 74(8): 969-985 [PMID: 14672754]

32 Gutteridge JM. Lipid peroxidation and antioxidants as biomarkers of tissue damage. Clin Chem 1995; 41(12 Pt 2): 1819-1828 [PMID: 7497639]

33 Moro MA, Cardenas A, Hurtado O, Leza JC, Lizasoain I. Role of nitric oxide after brain ischaemia. Cell Calcium 2004; 36(3-4): 265275 DOI: $10.1016 /$ j.ceca.2004.02.011

34 Moncada S, Bolanos JP. Nitric oxide, cell bioenergetics and neurodegeneration. $\boldsymbol{J}$ Neurochem 2006; 97(6): 1676-1689 DOI: 10.1111/j.1471-4159.2006.03988.x

35 Adachi N, Lei B, Soutani M, Arai T. Different roles of neuronal and endothelial nitric oxide synthases on ischemic nitric oxide production in gerbil striatum. Neurosci Lett 2000; 288(2): 151-154 [PMID: 10876083]
36 Kaundal RK, Sharma SS. GW1929: a nonthiazolidinedione PPARgamma agonist, ameliorates neurological damage in global cerebral ischemic-reperfusion injury through reduction in inflammation and DNA fragmentation. Behav Brain Res 2011; 216(2): 606-612 DOI: 10.1016/j.bbr.2010.09.001

37 Zhan C, Yang J. Protective effects of isoliquiritigenin in transient middle cerebral artery occlusion-induced focal cerebral ischemia in rats. Pharmacol Res 2006; 53(3): 303-309 DOI: 10.1016/j.phrs.2005.12.008

38 Chen YH, Du GH, Zhang JT. Salvianolic acid B protects brain against injuries caused by ischemia-reperfusion in rats. Acta Pharmacol Sin 2000; 21(5): 463-466 [PMID: 11324448]

39 El Assar M, Angulo J, Rodriguez-Manas L. Oxidative stress and vascular inflammation in aging. Free Radic Biol Med 2013; 65: 380-401 DOI: $10.1016 /$ j.freeradbiomed.2013.07.003

40 Yin J, Tu C, Zhao J, Ou D, Chen G, Liu Y, Xiao $\mathrm{X}$. Exogenous hydrogen sulfide protects against global cerebral ischemia/reperfusion injury via its anti-oxidative, anti-inflammatory and anti-apoptotic effects in rats. Brain Res 2013; 1491: 188-196 DOI: 10.1016/j.brainres.2012.10.046

41 Hosomi N, Ban CR, Naya T, Takahashi T, Guo $\mathrm{P}$, Song XY, Kohno M. Tumor necrosis factoralpha neutralization reduced cerebral edema through inhibition of matrix metalloproteinase production after transient focal cerebral ischemia. J Cereb Blood Flow Metab 2005; 25(8):959-967 DOI: 10.1038/sj.jcbfm.9600086

42 Jung YS, Ha SK, Kim SD, Kim SH, Lim DJ, Choi JI. The role of adiponectin in secondary inflammatory reaction in cerebral ischemia. $\boldsymbol{J}$ Cerebrovasc Endovasc Neurosurg 2013; 15(3): 171-176 DOI: $10.7461 /$ jcen.2013.15.3.171

43 Bouziana S, Tziomalos K, Goulas A, Etaatzitolios A. The role of adipokines in ischemic stroke risk stratification. Int J Stroke 2016;11(4):389-398

DOI: $10.1177 / 1747493016632249$

44 Sugawara T, Fujimura M, Noshita N, Kim GW, Saito A, Hayashi T, Narasimhan P, Maier CM, Chan PH. Neuronal death/survival signaling pathways in cerebral ischemia. NeuroRx 2004; 1(1): 17-25 DOI: 10.1602/neurorx.1.1.17 
45 Faubel S, Edelstein CL. Caspases as drug targets in ischemic organ injury. Curr Drug Targets Immune Endocr Metabol Disord 2005; 5(3): 269-287 [PMID: 16178788]

46 Cohen GM. Caspases: the executioners of apoptosis. Biochem J 1997; 326 ( Pt 1): 1-16 [PMID: 9337844 PMCID: PMC1218630]

47 Rami, A.; Jansen, S.; Giesser, I.; Winckler, J. Postischemic activation of caspase- 3 in the rat hippocampus: evidence of an axonal and dendritic localisation. Neurochem. Int., 2003; 43(3): 211 - 223. doi: 10.1016/S01970186(03)00002-0.

48 Li J, Han B, Ma X, Qi S. The effects of propofol on hippocampal caspase-3 and Bcl-2 expression following forebrain ischemiareperfusion in rats. Brain Res 2010; 1356: 1123 DOI: $10.1016 /$ j.brainres.2010.08.012
49 Loetscher H, Niederhauser O, Kemp J, Gill R. Is caspase- 3 inhibition a valid therapeutic strategy in cerebral ischemia? Drug Discov Today 2001; 6(13): 671-680 [PMID: 11427377]

50 Bratton, S.B.; Cohen, G.M. Caspase cascades in chemically-induced apoptosis. Adv. Exp. Med. Biol., 2001, 500, 407 - 20. https://link.springer.com/chapter/10.1007/9781-4615-0667-6 63\#Abs1

51 Love S. Apoptosis and brain ischaemia. Prog. Neuropsychopharmacol. Biol. Psychiatry, 2003, 27(2), 267 - 82. doi:10.1016/S02785846(03)00022-8. 